\title{
UM CAMINHO DIDÁTICO PARA A FILOSOFIA ANTIGA NO ENSINO \\ MÉDIO
}

Mayã Gonçalves Fernandes Graduanda em Filosofia UnB

Resumo: Este artigo tem como proposta a sugestão de um percurso didático para o docente do ensino médio na ocasião em que o assunto a ser desenvolvido em sala de aula forem temas da filosofia antiga. Neste ponto, será utilizado, como exemplo de planejamento de aula, a discussão sobre mito e filosofia. Para isso, será exposta ao professor (a) a possibilidade de fazer o próprio material auxiliar sobre o assunto, concebendo o livro didático como ferramenta essencial nesse preparo da disciplina.

Palavras-chaves: material didático; planejamento de aula; mito e filosofia

Abstract: This article have as proposal a sugestion of a didact route for the docent of high school, when the occasion the subject to be developed in classroom are themes of ancient philosophy. In this point, will be utilized as an example of lesson planning, the discussion about myth and philosophy. For thir, will be exposed to the teacher the possibility to do (his/her) own auxiliary material about the subject, conceiving the didactic book as an essencial tool for this discipline preparation.

Keywords: didactic material; class planning; myth and philosophy

\section{Introdução}

Situar a filosofia na formação de estudantes do ensino médio brasileiro em pleno século XXI não aconteceria sem dificuldades. Quais temas abordar? Como é possível analisar a contribuição de cada conteúdo? Qual filosofia deve ser privilegiada nos três anos do ensino secundarista? Essas questões vêm sendo debatidas por filósofos 
contemporâneos $^{1}$ que pesquisam sobre ensino de filosofia e vêm sendo difundidas por docentes do ensino médio preocupados com o papel formativo dessa disciplina.

Consciente da variedade de conteúdos, o professor pode optar por privilegiar uma linha de pesquisa inserida na tradição filosófica. Para dificultar a situação, ao docente de filosofia, independente da sua formação dentro da universidade, compete o domínio de uma parcela da tradição filosófica e, sobretudo, a compreensão da especificidade de cada uma dessas filosofias. Desse modo, o professor poderia explicar, por exemplo, de maneira (metodologicamente) semelhante a ética, a metafísica, a epistemologia, o existencialismo, o tomismo, a fenomenologia ou as filosofias de Platão, Descartes, Marx (CERLETTI, 2009, p. 16). Porém, mesmo conservando o valor filosófico de cada tema e filósofo, não é preciso ir a fundo para compreender que, como Cerletti (2009) demonstra, não existe uma “didática geral” para utilizar como ferramenta universal no ensino de filosofia.

Ao lecionar para uma turma de primeiro ano do ensino médio, o professor pode deparar-se com a necessidade de expor acerca da formação do mundo ocidental. Antes de elencar os três filósofos canônicos, Sócrates, Platão e Aristóteles², por que não começar com o imaginário inicial da filosofia, ou com O debate entre o mito e o lógos, tal como as suas rupturas e continuidades? Afinal, a razão evolui do mito? A filosofia nasce da mitologia? Como responder essas questões e quais os possíveis caminhos a trilhar? Quais os materiais que posso reservar para compor meu arsenal didático quando se trata da antiguidade?

É preciso lembrar que o professor deve ensinar além da maneira como as didáticas definem a filosofia. Isso significa ir além da definição formal de filosofia, já que, depois, poderá optar por prosseguir com uma metodologia diferente das que se utilizam dos fundamentos ou do contexto dessa definição, como costuma ser usual em muitos cursos. Entretanto, o docente é quem escolhe qual vínculo construirá entre professores e estudantes, e a construção desse vínculo torna-se decisiva para a existência do filosofar (CERLETTI, 2009, p. 18). No caso da filosofia antiga, o

\footnotetext{
${ }^{1}$ Alejandro Cerletti em seu texto O ensino de Filosofia como problema filosófico (2009), dedica boa parte de seu livro a problematização e criação de hipóteses para a resolução de questões acerca da utilidade da filosofia no ensino médio.

${ }^{2}$ Em um questionário repassado para 200 alunos na escola da cidade de Sobradinho-DF, participante do Projeto PIBID, uma quantidade significativa de estudantes apontaram Sócrates, Platão e Aristóteles como os filósofos mais vistos no decorrer de sua formação filosófica.
} 
professor poderá utilizar uma abordagem multidisciplinar, ao perceber que para fazer uma análise da antiguidade é preciso compreender que história, teatro, literatura e filosofia caminham juntos na pesquisa sobre o mundo antigo. Assim, além de realizar o movimento de regresso na história, o docente tem a oportunidade de perceber o kairós, isto é, a possibilidade de apreender a conjuntura que é ensinar a origem do pensamento ocidental, estando à margem desse pensamento (CORNELLI, 2012, p. 32). Essa oportunidade deve dar importância à situação marginal que o Brasil vivencia em relação ao ocidente e, a partir disso, o docente pode observar as releituras, remodelações da tradição, o sincretismo que ocorreu com as tradições indígenas e africanas, além de outras tradições incorporadas recentemente.

Através do sincretismo de tradições, deve aparecer ao professor uma questão fundamental antes de adentrar na filosofia antiga: nós sofremos grande influência da Grécia Antiga. Porém, temos que perceber que essa influência não é única, e a relação que estabelecemos com ela ao perceber que o Brasil está à margem desse pensamento não deve acentuá-lo como tradição principal e sim como componente desse emaranhado de experiências.

Desse modo, este trabalho tem como objetivo geral sugerir ferramentas para o professor do ensino médio, que diante da tradição filosófica, tem dificuldade no desenvolvimento de um tema específico e na construção de seu arsenal didático ${ }^{3}$. Para elucidar a proposta, o conteúdo de filosofia antiga - Mito e Filosofia - será exposto como exemplo de conteúdo de um curso introdutório para o ensino médio. Ao longo do material proposto, o docente encontrará fontes primárias (contribuição em língua vernácula), às quais poderá recorrer durante o planejamento das aulas. As fontes secundárias, por sua vez, servirão como auxílio para o aprofundamento na temática e elaboração de outros materiais didáticos para os estudantes.

\section{Do mito ao lógos}

\footnotetext{
${ }^{3}$ A noção da junção de ferramentas didáticas como arsenal aparece no livro de Silvio Gallo, Metodologia do ensino de filosofia, 2011, p. 147.
} 
Pontuar a origem do termo mythos e seu significado nem sempre é fácil e simples. Na origem, mythos não se opõe à lógos. As duas palavras convergem à significados próximos, como "palavra", "relato" (VERNANT, 1996, p. 14). Ter como pensamento inicial que esse termo, ao longo dos séculos, sofreu modificações e reconfigurações de seu significado inicial já é um grande passo. Hoje é possível compreender mito definido como um relato tradicional suficientemente importante para ser conservado e transmitido ao longo das gerações no interior de uma cultura. Ele tem por especificidade relatar histórias de heróis, ações dos deuses e seres lendários, cuja situação encontra-se em outro tempo que não o nosso, um passado diferente daquele que trata a pesquisa histórica (VERNANT, 1996, p. 9). Nas salas de aula, o mito apresentase como uma possível origem do pensamento ocidental, caracterizado como um compêndio de contos e lendas, ou colocado nas estantes das religiões (FERRY, 2009, p. 23). Diante dessa acusação, deve-se esclarecer que, enquanto tradição comum de toda uma civilização e religião politeísta, a mitologia não deixa de ser uma narração, uma tentativa grandiosa de responder à questão da vida boa com lições de sabedoria sob a forma de literatura, de poesia e de epopeia, mais do que tecido em argumentos abstratos. Para Ferry (2009), é “essa dimensão indissoluvelmente tradicional, poética e filosófica da mitologia que a torna tão interessante até os dias de hoje”.

Entretanto, alguns filósofos alegaram que existe uma antiga "querela” entre o mito e a filosofia, que deve ser melhor explorada. Tal questão, impulsionada por Platão ${ }^{4}$, afirma um ressentimento entre os filósofos e os poetas, e a distinção evidente entre os modos de conhecimento. Porém, essa concepção vem com o tempo perdendo credibilidade (MOST, 2010, p. 131), o que possibilita aos críticos de Platão questionar a veracidade da representação do contexto histórico da época pelo filósofo. Afinal, será que para os poetas existia essa "querela", ou era um debate catalisado por questões pessoais?

No intuito de prosseguir com a discussão, formaram-se dois grupos críticos: a) o que adota essa intriga entre os filósofos e os poetas e legitima o protagonismo de Platão não somente como filósofo, mas também como historiador e autoridade que reflete, de forma verídica, a realidade de seu tempo; b) o que acredita que não se deve considerar Platão como um reflexo de seu tempo (MOST, 2010, p. 132), já que não existem

\footnotetext{
${ }^{4} 1$ República; Íon, Banquete, Fedro, Leis.
} 
evidências ${ }^{5}$ variadas que embasem este certame entre o discurso filosófico e o mítico. Quanto ao primeiro grupo crítico, é sugerido, em estudos modernos, que tal querela realmente existiu e que é antiga, anterior a Sócrates e a Platão. De todo modo, aparentemente, essa relação entre mito e filosofia gera desconforto não somente entre os estudiosos da área, podendo levar o estudante a não compreender o conteúdo. Cabe ao professor questionar em qual sentido a poesia diverge da filosofia?

A poesia, em sua parte discursiva que é o mito, e a filosofia se diferenciam do seguinte modo: a) o mito se refere a um conjunto de práticas narrativas de histórias de um grupo social específico, transmitidas ao longo de uma tradição. O discurso sobre essa narrativa também pode ser caracterizado como mito, isto é:

Há um ramo do saber filosófico e científico que estuda a origem, o desenvolvimento e a natureza dos mitos, em si mesmo e na sua relação com outros tipos de discursos. Seja no primeiro ou no segundo sentido, falar de mitologia remete necessariamente a uma posição de pesquisa (MARQUES, 1994, p. 19-20).

O século XI a.C foi para a Grécia o princípio de um período obscuro, de onde vão emergir obras atribuídas a Homero. Homero é um poeta, isto é, fabricante de mitos, de modo que Platão associa sistematicamente poietés a mythólogos, e poíesis a mythología (BRISSON, 2014, p. 8).

Todos os mitos gregos que conhecemos nos foram transmitidos pelos textos literários, históricos, filosóficos. As versões mais antigas apareceram na época homérica ou de outros ciclos, cujos fragmentos nos chegaram, e nas diversas formas de poesia sapiental, coral, lírica, trágica. Sua ocorrência depende sempre do contexto das obras nas quais estes mitos estão inseridos (VERNANT, 1996, p. 13). Neste sentido, a literatura não aparece desacompanhada, pois é musicalmente recitada para um auditório, em festas comuns ou privadas. O caráter lúdico da poesia apresenta uma gama de possibilidades para o professor do ensino médio, e, como ferramenta didática, a poesia poderá unir várias áreas do conhecimento, como arte e música, dependendo de seus objetivos. A filosofia, em sua diferença específica do mito, opera através da manipulação de conceitos. Seu modo de apreensão é o do esforço da construção do

\footnotetext{
${ }^{5}$ Uma das poucas evidências das críticas aos poetas está, sobretudo, em Xenófanes. São críticas contra Homero e Hesíodo e, também, contra a teologia épica sobre o criticismo do próprio Platão ao relato dos deuses pelos poetas, no livro 2 da República (MOST, 2010,p.133). Entretanto, Xenófanes escreve seus versos na mesma métrica que os poetas por ele criticados, e essas críticas partiam da divergência no discurso da "verdade" que não era unânime.
} 
discurso progressivo, argumentativo e demonstrativo, satisfazendo a sua vontade de manter uma linguagem conceitual (MARQUES, 1994, p.33).

O saber, enquanto prática discursiva, tem pretensão à superação da finitude e da precariedade, torna-se busca da verdade sobre o mundo, verdade que carrega junto consigo uma potência de persuasão e de dominação de outros homens (MARQUES, 1994, p. 30). O poeta evoca os deuses, principalmente minemosine (memória), para repassar essas informações. Através do "transe”, o poeta aliena sua identidade e evoca em sua boca palavras que os deuses deveriam emitir (BRISSON, 2014, p.9). Todo o corpo é mobilizado para evocar o além. No entanto, a imitação colocada em ação pelo poeta ou pelos intérpretes

tem por objetivo último suscitar a identificação do público nos seres evocados diante de si. Ora, essa vontade de modificar o comportamento de uma massa de seres humanos coloca imediatamente um problema ético e político (BRISSON, 2014, p. 9).

Para Brisson, essa é a verdadeira questão que permeava a filosofia e a poesia, pois o poeta, ao ir até o público e apresentar modelos de seres que ele evoca, pode ser considerado um educador (BRISSON, 2014, p. 10). Quando Platão resolve banir os poetas de sua cidade ideal, elaborada na República, ele se queixa, sobretudo, do valor educativo que Homero e Hesíodo têm na sociedade.

Compreendendo essa questão, o professor poderá traçar uma trajetória em que, se tratando da relação entre mito e filosofia, existem duas perspectivas que a explicam. E, durante a ministração de um curso básico sobre o assunto, tais perspectivas podem servir de metodologia para abordar essa trajetória. A primeira diz respeito à relação descontínua e radical da passagem do mito ao lógos, sendo o primeiro negado e suprimido pelo segundo. Esta superação do mito pelo lógos foi chamada "milagre grego”. A segunda observa certa continuidade entre o mito e a filosofia, não existindo uma passagem, ou abandono por uma das partes, mas uma relação dialética entre eles. Existe uma transposição dos temas míticos ao plano do pensamento discursivo, onde há “rupturas e descontinuidades” (MARQUES, 1994, p. 22). Nessa visão, há um lógos no mito, como existe sobrevivência do mito no lógos. Consequentemente, o mito contém uma sintaxe e uma semântica própria, que deve ser desvendada. 
Através desse fio condutor, o professor seguramente conseguirá abordar os cânones da filosofia antiga (Platão e Aristóteles), sem deixar à margem Homero e Hesíodo, como componentes fundamentais para compreender o mundo grego, e as tragédias gregas. Neste percurso, o professor poderá se deparar com obras indicadas no Programa de Avaliação Seriada ${ }^{6}$, como a tragédia Antígona de Sófocles, no conhecimento de teatro, e Apologia de Sócrates, de Platão em Filosofia. Consequentemente, o docente conseguirá fermentar uma discussão em que cumprirá com as competências e habilidades das PCN's e do PAS.

\section{O que os livros didáticos têm a dizer sobre o conteúdo}

Ao escolher o conteúdo a ser trabalhado em sala de aula, o docente tem a difícil tarefa de buscar quais ferramentas utilizar para compor seus materiais didáticos e paradidáticos. Como fazer dos recursos didáticos instrumentos para um ensino de filosofia que seja um convite ao pensamento? (GALLO, 2011, p. 141).

O professor de filosofia busca ensinar como um convite à experiência filosófica do pensamento conceitual faz uma atividade dessa natureza: vai "colecionando" elementos os mais diversos, que poderá utilizar como estratégias de sensibilização dos alunos, textos de filósofos que poderá utilizar numa investigação na história da filosofia, em busca de elementos para a conceituação. Ao longo do tempo, colocando coisas em seu "saco", o professor vai criando todo um arsenal de recursos didáticos, que serão usados na medida da necessidade, no trabalho concreto com cada turma diferente de estudantes (GALLO, 2011, p. 142)

Cada professor, a partir de sua própria experiência com o tema a ser abordado, tem a liberdade de preparar um arsenal com elementos didáticos. Essas ferramentas variam e o livro didático mostra-se como um forte aliado, ao considerarmos que esse material é distribuído gratuitamente em todas as escolas de rede pública.

No Distrito Federal, dentre as obras obrigatórias, são utilizados três obras didáticas de filosofia no ensino médio: Filosofando: Introdução à Filosofia, de Maria Lúcia de Arruda Aranha e Maria Helena Pires Martins; Iniciação à Filosofia, de Marilena Chauí; Fundamentos de Filosofia, de Gilberto Cotrim e Mirna Fernandes.

\footnotetext{
${ }^{6}$ Para mais informações: http://www.cespe.unb.br/pas/
} 
Ao analisar os três livros foi possível constatar, que: 1) todos falam sobre o tema mito e filosofia; 2) conseguem apresentar um panorama histórico em que essa conversação está inserida; 3) existe uma série de elementos didáticos que podem auxiliar o professor em sala de aula.

Por mais que todos carreguem consigo a conversação entre mito/filosofia, alguns cedem mais espaço para o debate. Na obra Introdução à Filosofia, o mito é superado pela filosofia, segundo as autoras, e essa transformação ocorrere de acordo com as mudanças culturais da época (ARANHA; MARTINS, 2013, p.24). O interessante dessa obra didática para o ensino médio é o incentivo ao questionamento de temas postos como verdade. Como exemplo, as autoras exploram o debate que existe sobre essa possível passagem do mito para a filosofia, expõem o "milagre grego" (ARANHA; MARTINS, 2013, p.25) e questionam a sua veracidade, além de deixar explícito para o leitor seu viés ideológico.

Os outros dois livros polarizam os dois conceitos, o tema em questão apresentase com a perspectiva de que ocorre uma evolução da filosofia através dos mitos. Diversas vezes é possível encontrar o mito caracterizado como manifestação religiosa, sobrenatural, além de optação por uma abordagem do mito como sendo pensamento irracional e superado através do nascimento da filosofia, que, diferentemente do mito, coloca-se no mundo através da racionalidade e realidade (COTRIM; FERNANDES, 2010, p. 96).

Perceba que, neste ponto, você, professor, deve estar se questionando qual perspectiva deve adotar. Todos os livros podem te auxiliar na aplicação do conteúdo. Durante o preparo das aulas será importante perceber que, dependendo do caminho que será trilhado, a abordagem filosófica, tal como o arsenal didático, se modificará. Ou seja, a utilização dos livros didáticos é relativizada de acordo com o conteúdo.

Ao longo das obras, surgem diversas dicas de filmes e obras de arte que podem compor o arsenal didático do professor ${ }^{7}$. Entretanto, é interessante compor, através dessas referências, seu próprio material e compartilhá-lo com os estudantes. O professor

\footnotetext{
${ }^{7}$ No livro Fundamentos da Filosofia é possível encontrar uma série de sugestões de filmes e textos que possam estar complementando o conteúdo proposto (pp. 83, 109, 139, 152, 216); Em Iniciação à Filosofia, além das sugestões de filmes, a obra conta com sugestões de literatura complementar, que certamente convida o professor a aprofundar seus conhecimentos. (pp. 369-372). O livro Filosofando: Introdução à Filosofia carrega consigo uma série de possibilidades de materiais didáticos complementares, como imagens, filmes, textos.
} 
saberá quais são suas necessidades para lecionar o conteúdo e terá em mente que o livro didático, as músicas e os filmes funcionam como complemento para a aula. O texto filosófico deve ser o protagonista que só conseguirá compor uma ótima peça com a ajuda dos coadjuvantes.

\section{Conclusão}

Como é sabido, buscar maneiras diferenciadas para abordar um conteúdo de filosofia é necessário para o docente do ensino médio. No entanto, esse professor pode se questionar sobre quais métodos e conteúdos estão disponíveis para o conhecimento sobre o tema para o preparo satisfatório, utilizando um arsenal didático que possa favorecer a manipulação de uma aula.

Como exemplo de discussão, esse texto trouxe um esboço inicial sobre o debate que há entre o mito e a filosofia, considerando as duas leituras críticas que divergem entre si: a primeira adota as diferenças da poesia e da filosofia e a superação, quase que milagrosa, do pensamento mítico para o horizonte racional; e a segunda insiste na impossibilidade de compreender Platão como um relator fiel de seu tempo, e na existência de um raciocínio para o mito que permanece unido ao pensamento filosófico. Para o professor, a importância da compreensão desse debate consiste em conhecer caminhos possíveis pelos quais pode prosseguir de acordo com seus interesses ao longo do ano letivo.

Todo tema de filosofia discutido no ensino médio pode ser enriquecido com um bom arsenal didático. Esse material pode ser preparado pelo professor, considerando a interdisciplinaridade do tema, bem como a sua facilidade em manusear os materiais. Dito isso, o livro didático oferecido pelo Ministério da Educação pode ser um forte aliado tanto para o ensino do conteúdo, quanto para o fomento da pesquisa na área. Outros materiais, como películas, livros, obras de arte, música, podem ser utilizados, cabendo ao professor saber dosar a quantidade adequada de cada material. Para isso, estar ciente de todo o debate em torno do ensino de filosofia se faz necessário e a contribuição de cada docente, independente da sua linha de pesquisa, é valiosa.

\section{Referências}




\section{Primárias:}

Ciências humanas e suas tecnologias / Secretaria de Educação Básica. Orientações curriculares para o ensino médio. Brasília: Ministério da Educação, Secretaria de Educação Básica, 2006.

CERLETTI, Alejandro. O ensino de Filosofia como problema filosófico. Belo Horizonte: Autêntica Editora, 2009.

GALLO, Silvio. Metodologia do Ensino de Filosofia: uma didática para o ensino médio. São Paulo: Papirus editora, 2011.

\section{Secundárias:}

BRISSON, Luc. Introdução à Filosofia do Mito. São Paulo: Editora Paulus, 2014.

CORNELLI, Gabriele. História da filosofia antiga: começar pelo diálogo. In CORNELLI, Gabriele; CARVALHO, Marcelo; DANELON, Márcio. Coleção Explorando o Ensino: Filosofia. Brasília: Ministério da Educação, 2010.

------------, A outra margem do pensamento ocidental: o ensino da filosofia antiga no Brasil em tempos de globalização. In CORNELLI, Gabriele; CHEVITARESE, André Leonardo; SILVA, Maria Aparecida de Oliveira. Tradição Clássica e o Brasil. Brasília: Archai, 2008.

-------------, Viver e ensinar: modalidades marginais da história da filosofia antiga. In ROCHA, Sandra Lúcia Rodrigues. Cinco ensaios sobre a antiguidade. São Paulo: Annablume, 2012.

GONÇALVES, Ana Teresa Marques; SILVA, Gilvan Ventura da. O ensino de História Antiga nos livros didáticos brasileiros: balanço e perspectivas. In CORNELLI, Gabriele; CHEVITARESE, André Leonardo; SILVA, Maria Aparecida de Oliveira. Tradição Clássica e o Brasil. Brasília: Archai, 2008.

HADOT, Pierre. Elogio da Filosofia Antiga. Tradução de Flávio Fontenelle Loque e Loraine Oliveira. São Paulo: Edições Loyola, 2012.

Pierre. Elogio de Sócrates. Tradução de Loraine Oliveira, Flávio Fontenelle Loque. São Paulo: Edições Loyola, 2012.

FERRY, Luc. A Sabedoria dos Mitos Gregos: Aprender a viver II. Rio de Janeiro: Objetiva, 2009.

KOHAN, Walter. Filosofía, la paradoja de aprender y enseñar. Buenos Aires: Libros Del Zorzal, 2008.

2004.

. Filosofia: caminhos para seu ensino. Rio de Janeiro: DP\&A,

MARQUES, Marcelo P. Mito e Filosofia. Núcleo de filosofia Sônia Viegas. Caderno de Textos n.2, 1994.

MOST, Glenn. Que antiga querela entre a poesia e a filosofia? Revista Organom, Rio Grande do Sul, v.24 n. 49, p. 129-153, 2010. 
Mayã Gonçalves Fernandes

OBIOLS, Guillermo. Uma introdução ao ensino da Filosofia. Tradução de Sílvio Gallo. Ijuí: Editora Unijuí, 2002.

VERNANT, Jean-Pierre. Frontières $d u$ Mythe. In. VERNANT, Jean-Pierre ET GERGOUD, Stella. Mythes Grecs au Figuré de l'Antiguité au Baroque. Paris: Gallimard, 1996. 